\title{
The Treatment of Tuberculoid Leprosy
}

\author{
G. A. RYRIE.
}

Until recently the standard treatment for tuberculoid cases in Sungei Buloh has been the subcutancous injection of esters combined with intradermal injections at the lesion site. It has become growingly apparent, however, that intradermal treatment benefits mainly the subactive cases which are only a very small proportion of the tuberculoids here. Chinese in Malaya lo not appear to tolerate intra(lermal esters nearly so well as Indians.

A series of experiments therefore was conducted to ascertain the best method of treating active tuberculoid leprosy. The experiments were indicated over a period of four months. For each experiment twenty five male adlults were chosen. The Sedimentation Rate was taken once a fortnight but was not found to be of similar value to rates taken in similar experiments in cutaneous cases. Periodic smears were not taken during the experiment as the normal variation in bacillary content of tuberculoid lesions makes assessment difficult. Two separate observers made (laily notes on the cases.

The question arose to begin with as to whether the same results could be obtained with no treatment as with any specific therapy. For this purpose twenty five cases were given normal saline twice weekly in five cc. (loses subcutaneously. The "treatment" proved popular and at the end of one month there was subjective improvement in $100 \%$ of cases. By the end of three months many of them were becoming doubtful. By the end of the fourth month the position was as follows:-

Patients oz'n opinion: stationary 7 : improverl 10); worse 5 : (three cases had (lropped out with intercurrent ailments).

Observers' Opinion: stationary 7; slightly improved 5: slightly worse 10 .

In no case was there any marked deviation from the initial

to its painlessness (Chinese lo not have the Western fear of a needle). Quite frequently the psychological improvement was specific, e.g. the injections had improvecl the appetite, caused increased clearness of vision, banished chronic " numb-pains" and so on. It is however obvious from this experiment that active tuberculoid leprosy needs something more than general hygiene and psychotherapy.

A second group) were given injections of phthalic acid dissolved in hydnocarpus oil (3 grains of phthalic acid in 
5 cc. of hydnocarpus oil). Five cc. of the mixture were injected sulocutaneously twice a week.

All patients cleveloped acute inflammation at the site of injections. Two had to be admitted into hospital with large abscesses. Nine others had multiple abscesses requiring daily outpatient dressings. The experiment was terminated at the sixth week. It should indeed have been stopped before this.

A third group were given five cc. intradermal hyclnocarpus esters twice a week. No subcutaneous or intramuscular injections were given, the ol)ject being to determine the effect of intradermal treatment alone. This experiment had to be stopped after five weeks owing to the high inciclence of inflammation of an undesirable type.

This experiment confirmed my previous observation that intraclermal treatment is unsuital)le for active tuberculoids. This groul) after a suitable rest were then given subcutaneous infiltration of esters under the lesions. The same closes and times of injection were employed. Results were equally unfortunate, most cases developing pain and inflammation. The experiment was abancloned after four weeks.

The results in this somewhat unfortunate group confirmed my previous opinion that in acute tuberculoid leprosy in Chinese the local lesions should be left strictly alone. Late results of intradermal treatment in such cases have been equally disappointing.

This should not be considered as a condemnation of intra(lermal treatment of certain simple lepricles or of cutaneous leprosy. There is, however, a tendency to believe that leprosy treatment consists essentially of intradermal injections wherever possible. Such a tendency is bound to detract from the verv deserved repute of intraclermal treatment in cuteaneous cases.

A fourth experiment consisted of large doses of hydnocarpus oil. One cc. of oil was given for every ten pounds of body weight and injections were given subcutaneously twice a week. In this treatment it is advisable to divide doses of over ten cc. and inject in two different areas. One of this group weighed two hundred pounds and received therefore forty $\mathrm{cc}$. a week. Treatment was continued for four months. Result: stationary 2 ; improved 20 (one intercurrent illness); worse 2. Long before the four months was over most of the other groups were clamouring for this form of treatment. It will be noted that no local treatmient was given to the lesions. In one case shewing marked improvement, the lesion had been slowly advancing 
for twenty-seven years. Hyclnocarpus oil in the closes I have inclicated is the most effective treatment of acute tulberculoiid leprosy that we have been able to (liscover here.

Before (liscussing the next group it may be well to consicler what constitutes " improvement" in a tuberculoicl case. In the groups considered above, signs of improvement have been taken as (a) the checking of peripheral spreacl of the lesion and (b) the decrease or disappearance of activity in the lesion. The checking of peripheral spread is uncloubtedly a very clesirable clinical result; on the other hand a temporary increased activation in a tuberculoid lesion may be beneficial. Artificial activation of cases who have previously suffered from an attack of acute tuberculoid leprosy would obviously be unsuitable, and there is a very real danger in the activation of transitional or intermediate cases who are neither tuberculoid nor cutaneous. I (lo not think any general rule can be laid (lown: each case must be consiclered on its own merits.

A fifth group of active tuberculoids were given injections of $2 \%$ phthalic acid intravenously twice a week in closes of three cc. per ten pounds of bodly weight. After eight injections 21 out of the 25 cases shewerl definitely increased activity in the tuberculoid lesions.

This result together with general experience of the two drugs convinced me that phthalic acid and hydnocarpus oil act in opposite ways. Phthalic acid accelerates tuberculoid activity, hyclnocarpus oil controls it.

It was elecicled therefore to alter the phthalic acid group experiment and they now receive alternative courses of six subcutaneous injections of hydnocarpus oil (1cc. to ten pounds of body weight) followed by two intravenous injections of $2 \%$ phthalic acid (3 cc. for ten pounds). The injections as before are given at bi-weekly intervals. The experiment has been going on for three months and is marked in almost every case by the reactivation of the lesion after phthalic acid and its gradual retrogression during the following three weeks of intensive hylnocarpus oil treatment.

It is hoped that this alternative treatment will produce better ultimate results than those achieved by aclministration of hydnocarpus oil alone.

The effect of hydnocarpus oil in these active tulserculoids led me to a consideration of its use in acute tuberculoid leprosy. Acute tuberculoid leprosy in Chinese here may be, and often is, of a very violent character necessitating prolonged hospitalisation. Until recently we have considered hydnocarpus (lerivatives unsuitable in lepra fever (cutaneous 
reaction) and in acute tuberculoid leprosy-the two volcanic belts at either sicle of the leprotic range.

It was found, however, that treatment wth high doses of hydnocarpus oil has a (lefinite ameliorative effect in acute tuberculoid leprosy. Doses up to one cc. per ten pounds of body weight are well tolerated. In some cases we have given 1 cc. per five pounds of bolly weight subcutaneously twice a week for a short interval with beneficial results.

Phthalic acid in acute tuberculoid cases is contrainclicated as spurring on a resistance that has alrearly got beyond control.

While consiclerable research has been clone on the pathology, clinical appearance and significance of the tuberculoid process of leprosy, there has been a tendency to belittle the need for medical attention and to regard it as more or less self-healing. While this may be true in certain races, in others the results may be just as levastating as those of any cutaneous case, there is the ever present possibility of acute tuberculoid leprosy, and untreated or baclly treated cases may change over to cutaneous leprosy as is not infreculuently seen here. The response to the type of treatment I have outlined has moreover a very satisfactory effect on the morale of any settlement in both patients and staff alike. I have ventured therefore to (lescribe a system of treatment for tuberculoid leprosy. It can be summarised as follows :-

(i) For simple sulactive leprides or leprides of the indolent type, standard injections of ethyl esters combined with intraclermal injections.

(ii) For all lepricles with advancing periphery or lepride plaques with granulomatous activity-leave the local lesion strictly alone. Give sulocutaneous hydnocarpus oil in doses of $1 \mathrm{cc}$. per ten pounds of borly weight twice a week on courses of five months followed by one month's rest.

(iii) Hydnocarpus oil will control and damp down tuberculoid activity: phthalic acid will increase it. Where it is clesired to keej) a recurring flicker of tuberculoid activity, I suggest hydnocarpus oil in the dose given above for six injections followed by two injections of $2 \%$ phthalic acid, three cc. to ten pounds of body weight. The alternative treatment to be continued for five months followed by a month's rest. In individual cases the amounts of either clrug would require to be varied according to the lesion response.

(iv) In acute tuberculoid leprosy as much as $1 \mathrm{cc}$. of hydnocarpus oil to five pounds of body weight may be given twice a week until the acute phase is over. Phthali should not be given to acute tuberculoid cases. 
(v) A series of experiments including controls has been briefly (lescribed showing very satisfactory results from the methols summarised above. With a few exceptions the subjects of the experiment were Malayan Chinese.

Dr. Ryrie sencls a later note written on January 28th, 1938, in answer to (questions regarding further progress of the cases, and the possibly (lepressing effect of very large (loses of hydnocarpus esters:-

The twenty cases on large doses of hydnocarpus oil have continued to do well and it is now nearly a year since treatment was inaugurated. I think, however, it would be well to qualify my results by pointing out that Chinese leprosy in Malaya is not necessarily representative. For example intradermal treatment here does not have the wide range of usefulness that is claimed for it elsewhere; in Chinese Malayans it is usually effective in cases where there is any degree of cellular activity Again leprosy among these Chinese appears to have eruptive propensities that are less common elsewhere. A treatment therefore which ameliorates the cases I have described may not necessarily have general application. Malays, however, appear to respond well in tuberculoid cases.

With regard to apparent improvement being due to deterioration and lessening of reactive power. I would suggest that the lesions may subside either for good or evil, just as a temperature may subside on recovery or on the break-down of resistance. The general condition of my cases on hydnocarpus oil leads me very definitely to the belief that the apparent improvement is real and beneficial. (On the other hand we have other cases where paralysis and atrophy of cellular response obviously occur as a result of resistance break-down and are reactivated on general recovery. I myself am convinced, however, that the two processes are different.

The matter seems to me of very great importance. The greater part of the reputation of hydnocarpus derivatives is built on their effect on tuberculoid lesions. If the specific obliteration or recession of these lesions is harmful, then most workers are doing a considerable amount of lamage, slowly with bow doses and more quickly with high doses. Possibly my point of view is one-sided owing to the exhausting virulence of some of the tuberculoid cases here. I have ceased to regard tuberculoid leprosy as a manifestation of resistance but as a potentially dangerous sensitisation of the area involvedtissue-vindictiveness rather than tissue defence. 